\title{
ANALISIS PENERIMAAN PAJAK BEA BALIK NAMA KENDARAAN BERMOTOR DI SULAWESI UTARA
}

\author{
Ratu Inggrini ${ }^{1}$, Jenny $_{\text {Morasa }^{2}}$, Lidia Mawikere $^{3}$ \\ ${ }^{1,2,3}$ Akuntansi, Fakultas Ekonomi dan Bisnis, Universitas Sam Ratulangi, Jl. Kampus Bahu, Manado, 95115, \\ Indonesia \\ E-mail : Inggriniratu@gmail.com
}

\begin{abstract}
This study aims to find out the acceptance of tax on transfer fees of motor vehicles in North Sulawesi. This study used qualitative research methods. The result of the research revealed that the receipt of Transfer of Motor Vehicle Title I, especially two-wheeled vehicle (R2), experienced the biggest decrease in February 2017 of $22.10 \%$ and experienced the biggest increase in July 2107 of 41.65\%. For four-wheeled vehicles (R4) experienced the largest decline in December 2017 of 32.32\% and experienced the largest increase in July 2107 amounted to 46.29\%. then for the acceptance of Transfer of Motor Vehicle Name II II, especially for motorcycles (R2), the biggest decrease in March 2017 was 5.59\% and the highest increase was in January 2018 of 112.79\%. For four-wheeled vehicles (R4) experienced the largest decrease in April 2017 of 35.65\% and experienced the largest increase in October 2017 of $31.24 \%$
\end{abstract}

Keywords : Tax. public service

\section{PENDAHULUAN}

Pajak kendaraan bermotor merupakan salah satu bagian dari pajak provinsi. Di Sulawesi Utara, Pajak Kendaraan bermotor merupakan salah satu pajak provinsi yang memberikan kontribusi besar terhadap penerimaan pajak daerah. Pajak yang relatif potensial tersebut harus terus digali untuk mengoptimalkan penerimaan PAD. Faktor penting yang dapat membantu meningkatkan efektivitas penerimaan BBNKB yaitu kualitas pelayanan publik yang baik, kompetensi sumber daya manusia (SDM) aparatur yang berkompeten dibidang perpajakan sehingga kesadaran wajib pajak akan pentingnya membayar pajak terus meningkat. Melalui pelayanan publik, dengan didukung oleh kompetensi sumber daya manusia aparatur pajak untuk memenuhi kewajibannya membayar pajak merupakan hal yang penting dalam penerimaan pajak BBNKB Berdasarkan hasil penelitian terdahulu, maka peneliti tertarik untuk mengetahui sejauh mana pengaruh pelayanan publik, kompetensi sumber daya manusia aparatur dalam penerimaan pajak bea balik nama kendaraan bermotor.

Pengertian kualitas pelayanan publik terkandung suatu kondisi adanya kompetensi sumber daya manusia, dikaitkan dengan pelayanan aparat pajak. Anita Kristina (2009 : 28) menyatakan tugas pokok dan fungsi dari sumber daya manusia aparatur pajak pada intinya adalah menjadi abdi negara yaitu meningkatkan penerimaan negara dan menjadi pelayan masyarakat yaitu memberikan pelayanan yang baik kepada masyarakat, menjadi motivator yaitu memberdayakan masyarakat agar terlibat secara aktif dalam perpajakan, agar tugas pokok dan fungsi serta kewajiban tersebut dapat terlaksana dengan baik, maka harus didukung oleh SDM aparatur pajak yang memiliki pengetahuan, keterampilan di bidang perpajakan. 


\section{TINJAUAN PUSTAKA}

\subsection{Pajak Daerah}

Pajak daerah merupakan pajak yang ditetapkan dan dipungut oleh pemerintah daerah dengan peraturan daerh (PERDA), yang wewenang pemungutannya dilaksanakan oleh pemerintah daerah dan hasilnya digunakan untuk membiayai pengeluaran rumah tangga pemerintah daerah dalam melaksanakan penyelenggaraan pemerintahan dan pembangunan di daerah dan tercantum dalam Anggaran Pendapatan dan Belanja Daerah (APBD). Dalam hubungannya dengan pelayanan dibidang perpajakan, maka kompetensi SDM aparat perpajakan sangat stragis dalam upaya meningkatkan penerimaan dari sektor pajak.Anggiat dan Hadiati mengatakan bahwa Kemampuan (competency) aparatur meliputi pengetahuan (knowledge), ketrampilan (skill) dan sikap atau perilaku (attitude).dalam penelitiannya tentang Pengembangan SDM Aparatur melalui pendekatan soft HRM sebagai titik tumpu reformasi perpajakan menyatakan SDM Aparatur mempunyai peranan penting dalam mendukung suksesnya reformasi perpajakan.

Undang-undang nomor 28 tahun 2009 mengatur dengan jelas bahwa untuk dapat dipungut pada suatu daerah,setiap jenis pajak daerah harus ditetapkan dengan peraturan daerah, peraturan daerah tersebut sekurang-kurangnya mengatur mengenai;

a. Nama,objek dan subjek pajak;

b. Dasar pengenaan,tariff,dan cara penghitungan pajak;

c. Wilayah pemungutan;

d. Masa pajak;

e. Penetapan pajak;

f. Tata cara pembayaran dan penagihan pajak;

g. Kadaluwarsa penagihan pajak;

h. Sanksi administrasi;

i. Tanggal mulai berlakunya pajak;

Jenis pajak daerah pada wilayah administrasi provinsi atau kabupaten/kota yang bersangkutan. Berdasarkan Undang-undang tersebut ditetapkan jenis-jenis pajak daerah yaitu terdiri dari:

1. Jenis pajak provinsi terdiri atas:

a) Pajak Kendaraan Bermotor

b) Bea Balik Nama Kendaraan Bermotor

c) Pajak Bahan Bakar Kendaraan Bermotor

\subsection{Pajak Kendaraan Bermotor}

Kendaraan bermotor adalah setiap kendaraan yang di gerakkan oleh peralatan teknik yang ada pada kendaraan dan biasanya digunakan untuk orang dan barang selain daripada kendaraan yang berjalan di atas rel (Samudra, 2015:84). Pajak Kendaraan Bermotor menurut Undang-Undang no. 28 Tahun 2009 tentang pajak daerah dan retribusi daerah adalah "Pajak Kendaraan Bermotor adalah pajak atas kepemilikan dan/atau penguasaan kendaraan bermotor, tidak termasuk kepemilikan atau penguasaan kendaraan bermotor alat-alat berat dan alat-alat besar yang tidak digunakan sebagai alat angkutan orang dan/atau barang dijalan umum. Subjek Pajak Kendaraan Bermotor adalah orang pribadi, Badan, Pemerintah, Pemerintah Daerah, TNI dan Polri yang memiliki dan/atau menguasai Kendaraan Bermotor. Sementara itu wajib PKB adalah orang pribadi, Badan, Pemerintahan, Pemerintahan Daerah, TNI dan Polri yang memiliki dan/atau menguasai kendaraan bermotor dan atau kendaraan khusus atau alat-alat berat dan besar.

\subsection{Bea Balik Nama Kendaraan Bermotor BBNKB}

Pada Undang-Undang No. 28 tahun 2009 tentang pajak daerah dan retribusi daerah dijelaskan bahwa Bea Balik Nama Kendaraan Bermotor (BBNKB) adalah pajak atas penguasaan dan/atau penyerahan hak milik kendaraan bermotor sebagai akibat perjanjian dua 
pihak atau perbuatan sepihak atau keadaan yang terjadi kerena jual beli, tukar menukar, hibah, warisan, atau pemasukan ke dalam badan usaha, secara umum tujuan dari pembayaran BBNKB II, III, dan seterusnya ditujukan sebagai syarat untuk memperpanjang masa berlakunya Surat Tanda Nomor Kendaraan.

Dalam masa transisi pemberlakuan Undang-Undang Nomor 28 Tahun 2009 dewasa ini, pemungutan BBNKB di Indonesia saat ini didasarkan pada dasar hokum yang jelas dan kuat, sehingga harus dipatuhi oleh masyarakat dan pihak yang terkait. Pada BBNKB subjek pajak adalah orang pribadi atau badan yang menerima penyerahan kendaraan bermotor.Sedangkan wajib pajak BBNKB adalah orang pribadi atau badan yang menerima penyerahan kendaraan bermotor.Jika wajib pajak berupa badan, maka kewajiban perpajakannya diwakili oleh pengurus atau kuasa badan tersebut.

Peraturan Menteri Dalam Negeri tentang table perhitungan Dasar Pengenaan Pajak Kendaraan Bermotor Dan Bea Balik Nama Kendaraan Bermotor, NJKB ditetapkan dengan keputusan gubernur berdasarkan tabel yang ditetapkan oleh menteri dalam Negeri. Tarif BBNKB ditentukan berdasarkan tingkat penyerahan objek pajak yang terjadi dan jenis kendaraan bermotor yang diserahkan, Tingkat penyerahan kendaraan bermotor meliputi penyerahan pertama (yang berarti kendaraan baru) serta penyerahan kedua dan selanjutnya (yang berarti penyerahan atas kendaraan bekas).

BBNKB ditetapkan berdasarkan SPTPD yang diberitahukan oleh wajib pajak dengan menerbitkan SKPD atau dokumen lain yang dipersamakan, Apabila kendaraan bermotor mengalami perubahan bentuk atau penggantian mesin, maka wajib pajak diharuskan untuk melaporkan dan mengisi SPTPD dalam waktu 14 hari setelah selesai perubahan bentuk atau ganti mesin. Pembayaran BBNKB dapat dilakukan dikantor Kas Daerah atau bank atau tempat lain yang ditetapkan oleh gubernur kepala daerah setelah nota pajak atau SKP diterbitkan, Atas permohonan wajib pajak, gubernur kepala daerah dapat memberikan persetujuan kepada wajib pajak untuk mengangsur atau menunda pembayaran BBNKB setelah memenuhi persyaratan tertentu dengan dikenakan 2\%sebulan. Apabila BBNKB tidak dilunasi dalam waktu 30 hari setelah diterbitkannya notice dan/atau SKP, maka wajib pajak dikenakan denda sebesar $100 \%$ dari pajak terutang. Besaran pokok BBNKB yang terutang dihitug dengan cara mengalihkan tariff pajak dengan dasar pengenaan pajak, secara umum perhitungan BBNKB adalah sesuai dengan rumus berikut :

\section{Pajak Terutang $=$ Tarif Pajak $x$ Dasar Pengenaan Pajak}

\section{METODE PENELITIAN}

Data merupakan keterangan atau sumber informasi mengenai objek yang akan diteliti sebagai dasar dalam pengambilan keputusan Sujarweni (2014:6). Data kualitatif yang digunakan dalam penelitian ini yaitu berupa gambaran umum objek penelitian dan data tentang Analisis Penerimaan Pajak Bea Balik Nama Kendaraan Bermotor. Lokasi penelitian yang dilaksanakan pada Kantor Badan Pengelola Pajak dan Retribusi Daerah Sulawesi Utara. Waktu Penelitian yang dilaksanakan pada Awal Tahun 2018 dan Di Perkirakan selama 2 Bulan. Teknik yang digunakan dalam pengumpulan data adalah melalui penelitian ke kantor Dispenda melalui wawancara langsung ke BP2RD Provinsi Sulawesi Utara Terkait Efektivitas Penerimaan Pajak Bea Balik Nama Kendaraan Bermotor.

Sumber Data yang digunakan dalam penelitian ini adalah data primer yaitu data yang dikumpulkan langsung oleh peneliti. Data ini belum pernah dikumpulkan di periode waktu sebelumnya. Data ini merupakan data utama yang digunakan dalam penelitian, biasanya berbentuk observasi langsung dengan pihak terkait. Dalam penelitian ini, data primer didapatkan dengan cara wawancara langsung dengan Kepala UPTD Samsat Sulut dan datadata yang disimpan oleh Dinas Pendapatan Daerah Sulawesi Utara. 
Metode ini digunakan untuk mengetahui proses pemungutan pajak yang terjadi di Sulawesi utara. Cara pengumpulan data yaitu mengambil data pada kantor badan pengelola pajak dan retribusi daerah serta melakukan wawancara pada salah satu kepala kantor tersebut.

\section{HASIL ANALISIS DAN PEMBAHASAN}

4.1. Hasil Analisis

\subsubsection{Penerimaan Pajak Bea Balik Nama Kendaraan Bermotor I}

Bea Balik Nama Kendaraan Bermotor I (BBNKB 1) adalah suatu biaya yang dikenakan pada saat masyarakat membeli kendaraan bermotor baru yang keluar dari dealer.

Penerimaan Pajak Bea Balik Nama Kendaraan Bermotor R2 BBNKB-I

\begin{tabular}{|c|c|c|c|}
\hline No & $\begin{array}{c}\text { Bulan } \\
\text { Anggaran }\end{array}$ & Tahun & $\begin{array}{c}\text { Penerimaan R2 BBNKB-I } \\
(\mathrm{Rp})\end{array}$ \\
\hline 1 & Januari & 2017 & $6,065,941,775$ \\
\hline 2 & Februari & 2017 & $4,725,617,975$ \\
\hline 3 & Maret & 2017 & $6,552,260,175$ \\
\hline 4 & April & 2017 & $5,539,709,600$ \\
\hline 5 & Mei & 2017 & $5,083,567,625$ \\
\hline 6 & Juni & 2017 & $4,336,950,900$ \\
\hline 7 & Juli & 2017 & $6,143,255,475$ \\
\hline 8 & Agustus & 2017 & $7,708,789,450$ \\
\hline 9 & September & 2017 & $5,531,488,225$ \\
\hline 10 & Oktober & 2017 & $6,257,975,600$ \\
\hline 11 & November & 2017 & $6,053,099,850$ \\
\hline 12 & Desember & 2017 & $5,320,374,600$ \\
\hline 13 & Januari & 2018 & $6,913,037,250$ \\
\hline 14 & Februari & 2018 & $7,029,071,200$ \\
\hline
\end{tabular}

Sumber : Badan Pengelola Pajak dan Retribusi Daerah

Penerimaan Pajak Bea Balik Nama Kendaraan Bermotor R4 BBNKB-I

\begin{tabular}{|c|c|c|c|}
\hline No & $\begin{array}{c}\text { Bulan } \\
\text { Anggaran }\end{array}$ & Tahun & $\begin{array}{c}\text { Penerimaan R4 BBNKB-I } \\
(\mathrm{Rp})\end{array}$ \\
\hline 1 & Januari & 2017 & $20,279,324,200$ \\
\hline 2 & Februari & 2017 & $15,592,088,150$ \\
\hline 3 & Maret & 2017 & $18,694,103,200$ \\
\hline 4 & April & 2017 & $14,606,817,700$ \\
\hline 5 & Mei & 2017 & $14,119,227,700$ \\
\hline 6 & Juni & 2017 & $13,129,157,950$ \\
\hline 7 & Juli & 2017 & $19,207,298,200$ \\
\hline 8 & Agustus & 2017 & $26,278,820,750$ \\
\hline 9 & September & 2017 & $21,422,720,000$ \\
\hline 10 & Oktober & 2017 & $21,919,810,000$ \\
\hline 11 & November & 2017 & $23,876,205,000$ \\
\hline 12 & Desember & 2017 & $16,158,694,850$ \\
\hline 13 & Januari & 2018 & $18,781,580,450$ \\
\hline 14 & Februari & 2018 & $28,610,146,050$ \\
\hline
\end{tabular}

Sumber : Badan Pengelola Pajak dan Retribusi Daerah 


\subsubsection{Penerimaan Pajak Bea Balik Nama Kendaraan Bermotor II}

Bea Balik Nama Kendaraan Bermotor II (BBNKB 1I) adalah biaya kendaraan yang telah dijual oleh pemilik sebelumnya pada pemilik yang baru ketika sesuai dengan peraturan yang sudah diserahkan dalam bentuk penyerahan.

Penerimaan Pajak Bea Balik Nama Kendaraan Bermotor R2 BBNKB-II

\begin{tabular}{|c|c|c|c|}
\hline No & $\begin{array}{c}\text { Bulan } \\
\text { Anggaran }\end{array}$ & Tahun & $\begin{array}{c}\text { Penerimaan R2 BBNKB-II } \\
(\mathrm{Rp})\end{array}$ \\
\hline 1 & Januari & 2017 & $22,583,900$ \\
\hline 2 & Februari & 2017 & $18,924,650$ \\
\hline 3 & Maret & 2017 & $22,558,750$ \\
\hline 4 & April & 2017 & $14,515,500$ \\
\hline 5 & Mei & 2017 & $17,391,600$ \\
\hline 6 & Juni & 2017 & $20,199,500$ \\
\hline 7 & Juli & 2017 & $19,727,500$ \\
\hline 8 & Agustus & 2017 & $22,196,500$ \\
\hline 9 & September & 2017 & $16,866,800$ \\
\hline 10 & Oktober & 2017 & $22,136,446$ \\
\hline 11 & November & 2017 & $23,471,500$ \\
\hline 12 & Desember & 2017 & $16,217,800$ \\
\hline 13 & Januari & 2018 & $18,135,300$ \\
\hline 14 & Februari & 2018 & $16,352,060$ \\
\hline
\end{tabular}

Sumber : Badan Pengelola Pajak dan Retribusi Daerah

Hasil dari penerimaan kendaraan bermotor R2 BBNKB II dari bulan ke bulan selama satu Tahun Penuh terjadi penerimaan yang naik turun nya suatu penerimaan Pajak BBNKB II.

Penerimaan Pajak Bea Balik Nama Kendaraan Bermotor R4 BBNKB-II

\begin{tabular}{|c|c|c|c|}
\hline No & $\begin{array}{c}\text { Bulan } \\
\text { Anggaran }\end{array}$ & Tahun & $\begin{array}{c}\text { Penerimaan R2 BBNKB-II } \\
(\mathrm{Rp})\end{array}$ \\
\hline 1 & Januari & 2017 & $318,197,300$ \\
\hline 2 & Februari & 2017 & $289,079,000$ \\
\hline 3 & Maret & 2017 & $272,905,700$ \\
\hline 4 & April & 2017 & $275,771,500$ \\
\hline 5 & Mei & 2017 & $328,969,600$ \\
\hline 6 & Juni & 2017 & $197,033,307$ \\
\hline 7 & Juli & 2017 & $273,977,500$ \\
\hline 8 & Agustus & 2017 & $329,600,200$ \\
\hline 9 & September & 2017 & $129,210,500$ \\
\hline 10 & Oktober & 2017 & $160,828,550$ \\
\hline 11 & November & 2017 & $234,120,500$ \\
\hline 12 & Desember & 2017 & $191,973,200$ \\
\hline 13 & Januari & 2018 & $408,492,550$ \\
\hline 14 & Februari & 2018 & $260,048,700$ \\
\hline
\end{tabular}

Sumber : Badan Pengelola Pajak dan Retribusi Daerah

Hasil dari penerimaan kendaraan bermotor R4 BBNKB II dari bulan ke bulan selama satu Tahun Penuh terjadi penerimaan yang naik turun nya suatu penerimaan Pajak BBNKB II. 


\section{a. Penerimaan Pajak Bea Balik Nama Kendaraan Bermotor}

Hasil penelitian diketahui bahwa penerimaan Bea Balik Nama Kendaraan Bermotor I khususnya kendaraan bermotor roda dua (R2) mengalami penurunan terbesar pada bulan Februari 2017 sebesar $22.10 \%$ dan mengalami kenaikan terbesar pada bulan Juli 2107 sebesar $41.65 \%$. Untuk kendaraan bermotor roda empat (R4) mengalami penurunan terbesar pada bulan Desember 2017 sebesar 32.32\% dan mengalami kenaikan terbesar pada bulan juli 2107 sebesar 46.29\%. kemudian untuk penerimaan Bea Balik Nama Kendaraan Bermotor II khususnya kendaraan bermotor roda dua (R2) mengalami penurunan terbesar pada bulan Maret 2017 sebesar 5.59\% dan mengalami kenaikan terbesar pada bulan Januari 2018 sebesar $112.79 \%$. Untuk kendaraan bermotor roda empat (R4) mengalami penurunan terbesar pada bulan April 2017 sebesar 35.65\% dan mengalami kenaikan terbesar pada bulan oktober 2017 sebesar $31.24 \%$.

Dalam Proses penerimaan pajak bea balik nama kendaraan bermotor di Badan Pengelola Pajak dan Retribusi Daerah sudah dilaksanakan sesuai dengan peraturan perundang-undangan yang berlaku yaitu undang-undang No. 28 Tahun 2009 Tentang Pajak Daerah dan Retribusi Daerah dan Peraturan Daerah No. 7 Tahun 2011. Kualitas Pelayanan Publik dan Sumber Daya Manusia menjadi tolak ukur utama untuk meningkatkan penerimaan pajak bea balik nama kendaraan bermotor.

Kualitas pelayanan publik diatur dalam Undang-undang Nomor 25 Tentang Pelayanan Publik. Usaha yang dilakukan Badan Pengelola Pajak dan Retribusi Daerah Provinsi Sulawesi Utara untuk meningkatkan penerimaan pajak bea balik nama kendaraan bermotor yaitu dengan memberi fasilitas untuk peroses pembayaran BBNKB selain itu untuk orang cacat disediakan loket khusus agar dapat mempermudah pembayaran pajak BBNKB.Sedangkan untuk Sumber daya manusia Badan Pengelola Pajak dan Retribusi Daerah Provinsi Sulawesi Utara melaksanakan sosialisasi kepada masyarakat secara berkala. Usaha yang sudah dilakukan Badan Pengelola Pajak dan Retribusi Daerah Provinsi Sulawesi Utara sudah baik namun kesadaraan masyarakat yang menentukan meningkatnya penerimaan Bea Balik Nama Kendaraan Bermotor Di Sulawesi Utara.

\section{b. Kualitas Pelayanan Publik Dalam Peningkatan Penerimaan BBNKB}

Hal ini sejalan dengan penelitian yang dilakukan oleh Setiawan (2014) dengan judul Faktor-Faktor Yang Mempengaruhi Efektivitas Penerimaan Pajak Bea Balik Nama Kendaraan Bermotor Provinsi Bali yang menyatakan bahwa peningkatan penerimaan bea balik nama kendaraan bermotor dipengaruhi oleh pelayanan publik dan sumber daya manusia. Yuskar dan Yanti (2014) dengan judul Analisis Efektivitas Dan Faktor-Faktor Yang Mempengaruhi Penerimaan Pajak Kendaraan Bermotor Di Sumatera Barat menyatakan bahwa penerimaan Pajak Kendaraan Bermotor sangat efektif karena adanya dukungan dari masyarakat. Sedangkan Silvia dkk (2015) dengan judul Analisis Mekanisme Pemungutan Dan Penerimaan Pajak Kendaraan Bermotor Pada Kantor Samsat manyatakan bahwa makanisme yang digunakan dalam pemungutan pajak kendaraan bermotor pada Samsat. Bea Balik Nama Kendaraan Bermotor I (BBNKB 1) adalah suatu biaya yang dikenakan pada saat masyarakat membeli kendaraan bermotor baru yang keluar dari dealer. Bea Balik Nama Kendaraan Bermotor II (BBNKB 1I) adalah biaya kendaraan yang telah dijual oleh pemilik sebelumnya pada pemilik yang baru ketika sesuai dengan peraturan yang sudah diserahkan dalam bentuk penyerahan pada pihak lain wajib di laporkan kepada kantor badan pengelola pajak dan retribusi daerah untuk mengetahui jumlah biaya yang dikenakan dan pada saat jatuh tempo pembayaran pajak. 


\section{KESIMPULAN DAN SARAN}

\subsection{Kesimpulan}

Penelitian ini bertujuan untuk mengetahui proses mekanisme pajak bea balik nama kendaraan bermotor. Hasil penelitian sebagai berikut.

1. Mekanisme pemungutan BBNKB pada Badan Pengelola Pajak Dan Retribusi Daerah di Sulawesi Utara yakni dibagi menjadi 3 loket. Kepolisian, samsat dan jasa raharja. Di loket 1 yang bertugas adalah kepolisian, untuk melakukan cek fisik kendaraan baru, pendaftaraan, penelitian, dan penomeran kendaraan.Loket 2 yang bertugas adalah dispenda/jasa raharja, untuk penetapan pajak kendaraan bermotor dan penetapan jasa raharja. Loket 3 yang bertugas adalah kepolisian dan dispenda sebagai korektor,tempat pembayaran, dan penyerahan yang dilakukan oleh wajib pajak kendaraan bermotor.

2. Hambatan yang dihadapi oleh BP2RD Sulawesi Utara yakni banyak nya masyarakat yang membeli ataupun menjual kendaraan bermotor merasa terbebani melakukan pembayaran pajak sesuai ketentuan yang berlaku.

3. Upaya yang dilakukan untuk mengatasi hambatan yang dihadapi oleh BP2RD Sulut yakni melakukan operasi gabungan/razia 6 kali dalam 1 bulan,

\subsection{Saran}

Berdasarkan hasil penelitian maka dapat diberikan beberapa saran sebagai berikut.

1. Perlunya ditempatkan petugas-petugas tambahan sebagai pengarah lapangan untuk memantau pelaksanaan dilapangan

2. Diharapkan agar mengefisiensikan waktu dan memuaskan pelayanan untuk beberapa tahun kedepan pelayanan yang diberikan.

3. Perlunya peningkatan sumber daya agar dapat memanfaatkan pelayanan public dengan kemajuan teknologi yang ada untuk mengurangi kurangnya keterampilan dalam komputer maupun hal lainnya, sehingga memudahkan dalam pelayanann ketika wajib pajak membayar pajak kendaraannya agar lebih efisien dan efektif.

4. Untuk penelitian selanjutnya, diharapkan dapat meneliti lebih dalam tidak hanya terbatas pada variabel yang telah diteliti dalam penelitian ini, melainkan perlu adanya penambahan variabel lainnya serta diharapkan dapat menggunakan cakupan objek penelitian yang lebih luas. Selain itu, data penelitian harus lengkap sesuai dengan objek yang ditetapkan.

\section{DAFTAR PUSTAKA}

Lie, Anita. 2009. Cooperatif Learning. Jakarta : Grasindo

Undang-Undang Nomor 28 Tahun 2009 tentang Pajak Daerah dan Retribusi Daerah (Lembaran Negara Republik Indonesia Tahun 2009 Nomor 130)

Sujarweni, Wiratna. 2014. Metodologi penelitian: Lengkap, praktis, dan mudah dipahami.Yogyakarta: PT Pustaka Baru

Amelia Resi, Yuskar 2014. Analisis Kinerja Kantor Pelayanan Penyuluhan dan Konsultasi Perpajakan Terhadap Kepatuhan Wajib Pajak. E-Jurnal Dosen Fakultas Ekonomi Universitas Andalas 14.1, Sumatera Utara.

A, Sylvia., dan M, Lorraine. 2015. Konsep Klinis Proses-Proses Penyakit. Patofisiologi Edisi 6 Vol 2. Jakarta : EGC

Samudra. 2015. Perpajakan di Indonesia. Jakarta : PT Raja Grafindo Persada

Undang-Undang Nomor 25 Tahun 1992 Tentang Perkoperasian

Setiawan, M., Sunaryo. (2014) Faktor - faktor yang Mempengaruhi Sikap Konsumen dan

Minat Pembelian Produk Handbag Merek Tiruan. Jurnal aplikasi, 12 (4 
Undang-Undang Republik Indonesia Nomor 34 Tahun 2000 Tentang Pajak Daerah dan Retribusi Daerah. Tambahan Lembaran Negara Republik Indonesia Nomor 4048

El-Bakry, Hazem M. 2017. Proceeding of The 8th WSEAS International Conference on Education and Aducational Technology: Design of Quality Assurance Management System for E-Universities

Mardiasmo.2016. Perpajakan-Edisi Terbaru 2016. Penerbit Andi. Yogyakarta.

Koswara,E, 2000. Menyongsong Pelaksanaan Otonomi Daerah Berdasarkan UndangUndang Nomor 22 Tahun 1999: Suatu Telaahan dan Menyangkut Kebijakan, Pelaksanaan dan Kompleksitasnya. CSISXXIX Nomor 1,Jakarta. 